\title{
A case of pituitary apoplexy following posterior lumbar fusion surgery
}

\author{
Akın Akakın, MD, ${ }^{1}$ Baran Yılmaz, MD, ${ }^{1}$ Murat Şakir Ekşi, MD, ${ }^{2}$ and Türker Kılıç, MD, PhD1 \\ ${ }^{1}$ Department of Neurosurgery, Bahçeşehir University Medical School, Istanbul, Turkey; and 2Department of Orthopedic Surgery, \\ University of California, San Francisco, California
}

\begin{abstract}
Pituitary adenoma is a common primary brain neoplasm. Pituitary apoplexy (PA) is a rare complication of pituitary adenoma and occurs as the result of sudden tumor growth and following different comorbidities. The authors describe the first case of PA following posterior lumbar fusion surgery performed while the patient was prone. In patients with a preexisting pituitary adenoma, thorough clinical and laboratory investigations should be conducted using an interdisciplinary approach before any planned surgery. In unknown cases of pituitary adenoma, PA should be kept in mind for the differential diagnosis in a case with headache, nausea, vomiting, ophthalmoplegia, visual loss, and electrolyte imbalance concurrent with an ongoing disease state.
\end{abstract}

http://thejns.org/doi/abs/10.3171/2015.3.SPINE14792

KEY WORDS pituitary adenoma; pituitary apoplexy; lumbar stenosis; spinal fusion

$\mathrm{P}$ ITUITARY adenoma is a common primary brain neoplasm, with a prevalence of $22.5 \% .^{5}$ Pituitary apoplexy (PA) is a rare complication $(0.6 \%-21 \%)$ of pituitary adenomas, occurring as the result of sudden tumor growth $^{8,9,12,13}$ and having a male preponderance. It is most commonly observed in nonfunctional pituitary macroadenomas, secondly in prolactinomas. ${ }^{8,12}$ There are many proposed mechanisms for PA pathophysiology; however, its exact pathophysiology has not been completely understood. ${ }^{4,8}$ The clinical picture may be precipitous or insidious. Apoplexy could manifest with one or more of the following signs and symptoms, all of which could lead to a life-threating condition: headache, nausea, vomiting, ophthalmoplegia, visual loss, and electrolyte imbalance. . $^{8,14}$

We describe a patient with PA who presented with the sudden onset of headache and visual deterioration following posterior lumbar fusion surgery performed while the patient was prone.

\section{Case Report}

History and Examination

A 58-year-old man visited our clinic with long-lasting low-back and bilateral leg pain. He mentioned that it was very distressful to walk long distances more than 1 block away from his apartment. His medical and family histories were insignificant for diabetes mellitus, hypertension, or any malignancies. On neurological examination, he was fully alert and cooperated. There was bilateral hypesthesia over L-5 and S-1 dermatomal zones. He had Medical Research Council Grade 1/5 motor weakness in his right foot plantar flexion. His preoperative visual analog scale score was 9. On electromyography testing, there was bilateral chronic denervation along the L-5 and S-1 nerve roots. We observed lumbar spinal canal stenosis at the L-4 and L-5 levels on MRI. Stenosis was most severe at the L-5 level with protruding intervertebral disc herniation. His hemo- 
globin level was $15 \mathrm{~g} / \mathrm{dl}$, and other laboratory test results were within normal range.

\section{Operation}

We planned L-4 laminectomy, L-5 laminotomy, L5-S1 microdiscectomy, and bilateral L3-5 transpedicular fixation with arthrodesis. The surgery was uneventful. Total intraoperative blood loss was $250 \mathrm{ml}$.

\section{Postoperative Course}

Postoperative laboratory test values were within normal ranges. There was no additional neurological deficit immediately after surgery. At the 6th postoperative hour, the patient became lethargic with the sudden onset of headache and bilateral blurred vision. On reexamination, he had bilateral temporal hemianopia. Emergency CT displayed an intrasellar lesion with varying densities, extending upward to the optic chiasm (Fig. 1). There was no subarachnoid hemorrhage on CT; however, we still suspected both a preexisting pituitary adenoma and a giant aneurysm. We sent blood for a pituitary hormonal profile and electrolyte levels and performed contrast-enhanced brain MRI and MR angiography (MRA). The lesion had mass effect over the optic chiasm and cavernous segments of the bilateral internal carotid arteries (Fig. 2A). There was no aneurysm on MRA. We started corticosteroid replacement therapy because of possible PA. There was no electrolyte imbalance. The patient's pituitary hormone profile was normal.

On postoperative Day 1, the morning after the patient's clinical deterioration, we performed microsurgical decompressive surgery via the transsphenoidal route. The lesion was hemorrhagic and necrotic. No complications occurred. Histopathological analysis was compatible with PA within a chromophobic adenoma. Postoperative sellar MRI showed the optic chiasm had been decompressed (Fig. 2B). Postoperative hormone profile and electrolyte levels were in the normal range. The patient was discharged with an ongoing prednisolone replacement regimen. Four months after surgery, his visual acuity and visual field were better. His general status was good. There was no residual tumor on sellar MRI (Fig. 3).

\section{Discussion}

Pituitary apoplexy is a rare, life-threatening compli-

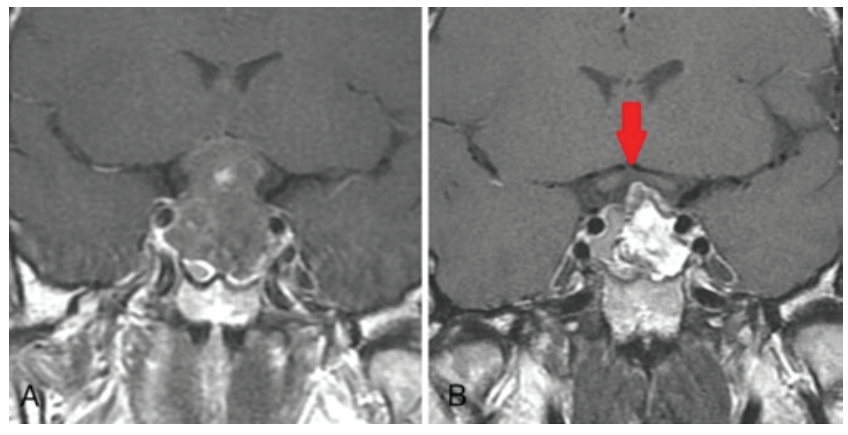

FIG. 2. Preoperative coronal contrast-enhanced sellar MR image depicts a huge pituitary lesion extruding from the sellar region and compressing the optic chiasm (A). Postoperative coronal contrast-enhanced sellar MR image shows the optic chiasm (red arrow) has been relieved with tumor and necrotic tissue excision (B). Figure is available in color online only.

cation of pituitary adenoma. Bailey described PA in an acromegalic patient in 1898. ${ }^{1}$ In 1950, Brougham and colleagues coined the term "pituitary apoplexy."3 Although PA occurs spontaneously, there are some predisposing factors such as head trauma, hypertension, sudden changes in arterial blood pressure, hormonal therapy, somatostatin analogs, dopamine agonists, diabetes mellitus, diabetic ketoacidosis, cardiac surgery, laparoscopic surgery, dynamic pituitary function tests, radiotherapy, anticoagulation, pneumoencephalography, repetitive coughing, transiently increased intracranial pressure, positive-pressure mechanical ventilation, and high altitude. . $, 3,6-8,10,12,13^{-13}$

Liu et al. described PA in a patient surgically treated for lumbar fusion via the anterior laparoscopic approach. ${ }^{6}$ They placed the patient in the Trendelenburg position and inflated his abdomen with $\mathrm{CO}_{2}$. They inserted 2 cages with bone graft into the L5-S1 intervertebral disc space. They stated that abdominal distension with $\mathrm{CO}_{2}$ had increased venous pressure and thus had increased intracranial pressure. They had performed their surgery with the patient supine. In our case, however, we performed an open posterior spinal fusion surgery while the patient was prone with underlying supporting chest rolls. Poon et al. conducted clinical research on patients who had undergone spine surgery in the prone position to understand the hemodynamic changes occurring during that kind of procedure. ${ }^{11}$ The authors found out that cardiac index, stroke volume, and mean arterial blood pressure values decreased sig-

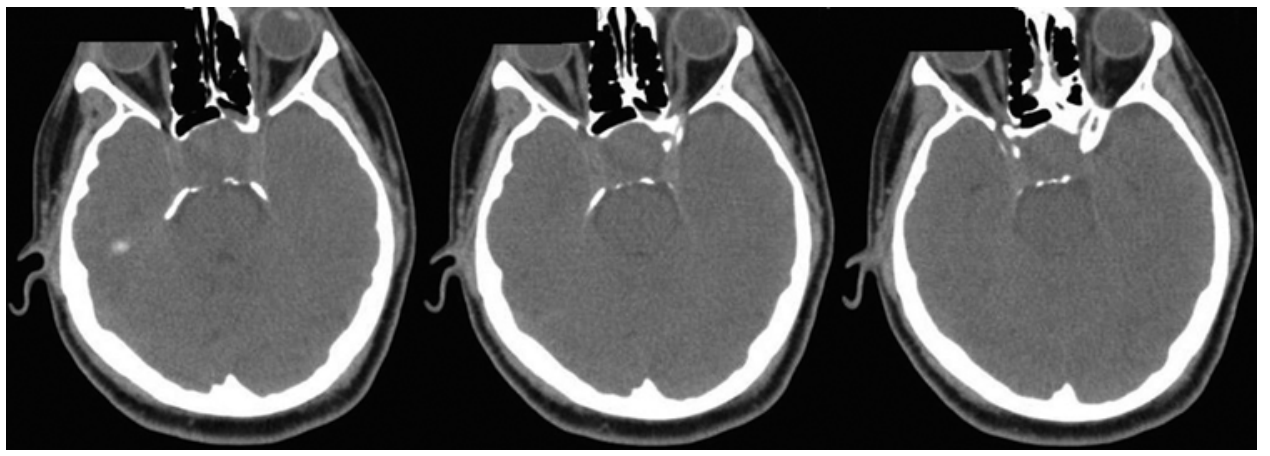

FIG. 1. Emergency CT was performed after the patient's signs and symptoms appeared following surgery. An irregularly bordered lesion in the sellar region has different densities within. 


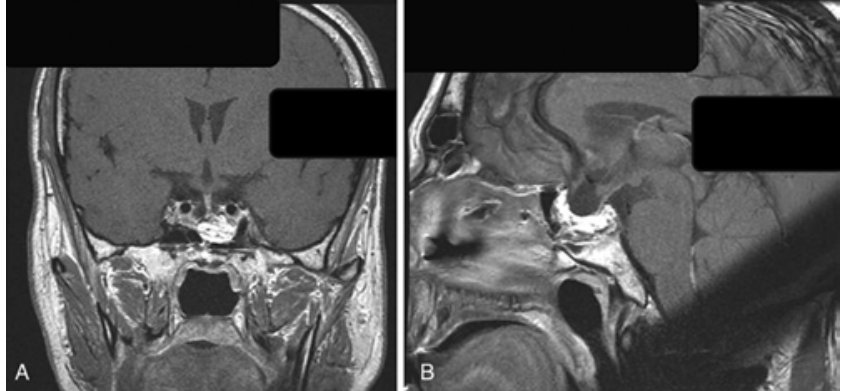

FIG. 3. Four-month postoperative coronal (A) and sagittal (B) sellar MR images show no residual tumor. The optic chiasm and pituitary infundibulum are free.

nificantly 10 minutes after the patients were placed prone. After 1 hour in the prone position, the patients' heart rate decreased and was accompanied by a further decrease in mean arterial blood pressure from the 10-minute time point, despite a stable stroke volume. They also observed that central venous pressure (CVP) was stable during the surgeries. As their study showed, 3 causes are possible in our featured case: decreased pulmonary compliance due to the prone position, chest roll compression, and inadequate preload. Blood loss in the surgery was limited to only $250 \mathrm{ml}$. Compensatory replacement with plasma extender was done, and CVP was stable throughout the surgery. During spine surgeries, patients' arms and legs stay in a lower position than their hearts while they are prone, so blood pooling may be the reason for decreases in preload and blood pressure. It is interesting that in addition to the prone position, positioning in the convex posture used for surgical purposes has been found to be important for reductions in the cardiac index. ${ }^{15}$ Decreased blood pressure in turn would have caused insufficient blood supply to the pituitary gland and adenoma, causing PA in our presented patient.

A full neurological reevaluation is vital for all neurologically deteriorating patients. However, lethargy is a very common problem that can block us from making accurate visual examinations. ${ }^{7}$ Computed tomography is an emergency-setting tool for immediately evaluating the brain. Hemorrhage can be detected on CT 3 days after the onset of PA..$^{10,13}$ Magnetic resonance imaging is the best evaluation tool after the diagnosis of PA on CT. Tumor, hemorrhage, and infarction can be better differentiated on MRI. The most important differential diagnosis to be considered is intracranial aneurysm, which may have devastating results if not approached cautiously. ${ }^{13}$ Sometimes subarachnoid hemorrhage presents with PA, which makes the differential diagnosis even more complicated. If CT or MRI is not sufficient in such a case, MR angiography or conventional angiography should be used to make the final diagnosis. ${ }^{13}$

There is no consensus over the treatment strategy for PA given its rare occurrence and different natural courses following onset. There are both conservative and surgical options. Conservative treatment includes corticosteroids, bromocriptine, or radiotherapy. ${ }^{13}$ Surgical management consists of 2 options: transsphenoidal and transcranial approaches. There is also argument about the time for sur- gery: immediate or early. Some authors have stated that the time for surgery does not affect the outcome of visual disturbances and have advocated early surgical decompression within 6-8 days of apoplexy., ${ }^{7,13}$ After surgery, ophthalmoplegia recovers better than visual field defects. ${ }^{8,10}$ Our patient's visual disturbances recovered long after the decompressive surgery. Transsphenoidal surgery is more successful than the transcranial approach (49\% and $42 \%$ success rates, respectively). ${ }^{13}$ We chose a transsphenoidal route. We waited one night to determine if our patient's hormonal status was normal and to be sure that he did not need any further hormonal and electrolyte supplements before the surgery for PA. If these factors are not taken into consideration and if deficiencies are not corrected before surgery, catastrophic surgical results could ensue. ${ }^{12,13}$ Diabetes insipidus, hypopituitarism, and rhinorrhea are possible complications and should be closely monitored after surgery. ${ }^{8,13}$

\section{Conclusions}

In patients with preexisting pituitary adenoma, thorough clinical and laboratory investigations should be conducted using an interdisciplinary approach before any planned surgery. In unknown cases of pituitary adenoma, PA should be kept in mind for the differential diagnosis in cases of headache, nausea, vomiting, ophthalmoplegia, visual loss, and electrolyte imbalance occurring after spinal surgeries.

\section{References}

1. Bailey P: Pathological report of a case of acromegaly, with especial reference to the lesions in the hypophysis cerebri and in the thyroid gland; and a case of hemorrhage into the pituitary. Philadelphia Med J 1:789-792, 1898

2. Brar KS, Garg MK: High altitude-induced pituitary apoplexy. Singapore Med J 53:e117-e119, 2012

3. Brougham M, Heusner AP, Adams RD: Acute degenerative changes in adenomas of the pituitary body-with special reference to pituitary apoplexy. J Neurosurg 7:421-439, 1950

4. Ebersold MJ, Laws ER Jr, Scheithauer BW, Randall RV: Pituitary apoplexy treated by transsphenoidal surgery. A clinicopathological and immunocytochemical study. J Neurosurg 58:315-320, 1983

5. Ezzat S, Asa SL, Couldwell WT, Barr CE, Dodge WE, Vance ML, et al: The prevalence of pituitary adenomas: a systematic review. Cancer 101:613-619, 2004

6. Liu JK, Nwagwu C, Pikus HJ, Couldwell WT: Laparoscopic anterior lumbar interbody fusion precipitating pituitary apoplexy. Acta Neurochir (Wien) 143:303-307, 2001

7. McFadzean RM, Doyle D, Rampling R, Teasdale E, Teasdale G: Pituitary apoplexy and its effect on vision. Neurosurgery 29:669-675, 1991

8. Möller-Goede DL, Brändle M, Landau K, Bernays RL, Schmid C: Pituitary apoplexy: re-evaluation of risk factors for bleeding into pituitary adenomas and impact on outcome. Eur J Endocrinol 164:37-43, 2011

9. Nielsen EH, Lindholm J, Bjerre P, Christiansen JS, Hagen C, Juul S, et al: Frequent occurrence of pituitary apoplexy in patients with non-functioning pituitary adenoma. Clin Endocrinol (Oxf) 64:319-322, 2006

10. Onesti ST, Wisniewski T, Post KD: Clinical versus subclinical pituitary apoplexy: presentation, surgical management, and outcome in 21 patients. Neurosurgery 26:980-986, 1990 
11. Poon KS, Wu KC, Chen CC, Fung ST, Lau AW, Huang CC, et al: Hemodynamic changes during spinal surgery in the prone position. Acta Anaesthesiol Taiwan 46:57-60, 2008

12. Semple PL, Webb MK, de Villiers JC, Laws ER Jr: Pituitary apoplexy. Neurosurgery 56:65-73, 2005

13. Turgut M, Ozsunar Y, Başak S, Güney E, Kir E, Meteoğlu I: Pituitary apoplexy: an overview of 186 cases published during the last century. Acta Neurochir (Wien) 152:749-761, 2010

14. White W, Liu SS: Pituitary apoplexy, in Carter L, Spetzler RF (eds): Neurovascular Surgery. New York: McGraw-Hill, 1995

15. Yokoyama M, Ueda W, Hirakawa M, Yamamoto H: Hemodynamic effect of the prone position during anesthesia. Acta Anaesthesiol Scand 35:741-744, 1991

\section{Disclosure}

Dr. Ekşi was supported by a grant from Tubitak (The Scientific and Technological Research Council of Turkey), Grant no. 1059B191400255.

\section{Author Contributions}

Conception and design: all authors. Acquisition of data: Akakın, Yılmaz, Kılıç. Analysis and interpretation of data: Ekşi, Y1lmaz. Drafting the article: all authors. Critically revising the article: all authors. Reviewed submitted version of manuscript: all authors. Approved the final version of the manuscript on behalf of all authors: Ekşi. Administrative/technical/material support: Akakın, Yılmaz, Kilıç. Study supervision: Kilıç.

\section{Correspondence}

Murat Şakir Ekşi, University of California, San Francisco, Spine Center, 500 Parnassus Ave., MU320 West, San Francisco, CA 94143-0728. email: muratsakireksi@gmail.com. 